\title{
Problems of nutritional assessment in the acute setting
}

\author{
J. P. Baxter \\ Department of Digestive Diseases and Clinical Nutrition, Ninewells Hospital and Medical School, Dundee DDI 9SY, UK
}

\begin{abstract}
Surveys have shown that $20-50 \%$ of hospital admissions suffer from nutritional depletion and that there is failure to recognize its existence and significance. More emphasis must be placed in clinical medicine on identifying subjects who are at high risk of developing disease-related malnutrition. There is a need to screen patients on admission to hospital to identify those at risk of nutrition-related complications. More formal determination of nutritional status should be carried out to define the nutritional status of the patient and to monitor changes in nutritional status during nutritional support. The most frequently used tests of nutritional status include dietary, anthropometric, biochemical and functional indices of nutritional status. It is important, and indeed is the skill of the nutritional care team (particularly the dietitian) to be able to evaluate these measurements, as many of them are affected by non-nutritional factors. There is no consensus on the best method for the accurate assessment of nutritional status. Practical difficulties arise with individual measurements and in their interpretation in the acute setting. The aim of the present paper is to identify the most relevant variables to measure in clinical medicine, and to discuss the limitations of their use in the acute setting.
\end{abstract}

Nutritional status assessment: Anthropometry: Body composition assessment: Biochemical markers

Surveys have shown that $20-50 \%$ of hospital admissions suffer from nutritional depletion (Bistrian et al. 1976; Hill et al. 1977; McWhirter \& Pennington, 1994), and that there is failure to recognize the existence of the problem because clinical staff are not trained to look for the signs (McWhirter \& Pennington, 1994; Lennard-Jones et al. 1995). Attempts have been made to correlate nutritional status with clinical outcome and complication rates. One of the first clinicians (Studley, 1936) to demonstrate the relationship between preoperative weight loss and post-surgical outcome found that patients with $>20 \%$ weight loss had a significantly higher post-operative mortality. It has been demonstrated in a literature review that, although there are many concurrent factors affecting clinical outcome and nutritional status, nutritional depletion increases the risk of related complications and death (Dempsey et al. 1988). Macronutrient deficiency is evident and micronutrient deficiency less common. More emphasis must be placed in clinical medicine on identifying subjects who are at high risk of developing disease-related malnutrition.

It has been recommended that all patients admitted to hospital are assessed for nutritional risk using one of the many protocols in existence (Sizer, 1996). The use of a formal nutritional screening tool for every admission is probably inappropriate and ineffective, but it may be more realistic to screen for nutritional risk based on further recommendations (Lennard-Jones et al. 1995). More formal clinical nutritional assessment may then be carried out by a dietitian or similarly-trained personnel. The objectives of such an assessment are: (a) to accurately define the nutritional status of the patient, (b) to define clinically relevant malnutrition, (c) to monitor changes in nutritional status during nutritional support (Bozzetti, 1987). Clinicallyrelevant malnutrition has been defined as: "the state of altered nutritional status that is associated with an increased risk of adverse clinical events such as complications or death' (Dempsey \& Mullen, 1987). Ideally, nutritional assessment should help determine the type and aggressiveness of nutritional support required for an individual patient, which should be timely and cost effective.

It is generally agreed that malnourished patients are at greater risk of developing nutrition-related complications. This awareness has led to the development of the new field of nutritional assessment. The 1970s saw the introduction of nutrition indices which were used to assess the nutritional status of hospitalized patients (Blackburn et al. 1977; Buzby

\footnotetext{
Abbreviations: BIA, bioelectrical impedance analysis; IGF, insulin-like growth factor; MAC, mid-arm circumference; MAMC, mid-arm muscle circumference; TSF, triceps skinfold thickness.

Corresponding author: Dr Janet P. Baxter, fax $+44(0) 1382$ 644972, email janetb@dth.nhs.scot.uk
} 
et al. 1980; Grant et al. 1981). Approximately 20 years later, there is no consensus on the best method for the accurate assessment of nutritional status. The aim of the present paper is to identify the most relevant indices to measure in clinical medicine and to discuss the limitations of their use in the acute setting.

The most frequently used tests of nutritional status include dietary, anthropometric, biochemical and functional indices of nutritional status. It is important, and indeed is the skill of the nutritional care team (particularly the dietitian) to be able to evaluate these measurements, as many of them are affected by non-nutritional factors.

\section{Screening for nutritional risk}

Specific groups of patients have been studied and identified as being at risk of protein-energy malnutrition. Nutritional screening is now common in many clinical areas, and many tools have been developed for this purpose. There remains, however, a need for a published universally-acceptable validated screening tool. A study conducted by a working party of the British Association for Parenteral and Enteral Nutrition (Lennard-Jones et al. 1995) found that half of the 454 ward nurses and two-thirds of the 319 junior doctors questioned had asked patients about recent unintentional weight loss before admission to hospital. This survey led to the identification of four basic questions to be asked of patients on admission to hospital. The recommendations are that every patient admitted to hospital should be asked the following questions.

Have you unintentionally lost weight recently?

Have you been eating less than usual?

What is your normal weight?

How tall are you?

On the basis of these questions, all patients should have been weighed and have their height measured. All answers and measurements should be documented in case notes, and those patients considered to be at risk of nutritional depletion should be referred for specialist assessment and advice.

Many hospitals or clinical units have developed 'in house' tools for detection of at-risk patients. One such tool has been adopted as a national standard (Reilly et al. 1995).

\section{Measurement of nutritional status}

'Nutritional status is the condition of the body resulting from the intake, absorption and utilization of food, as well as from factors of pathological significance. Nutritional status assessment usually includes anthropometric, dietary and biochemical measurement, clinical history and physical and other data' (World Health Organization, 1973).

Nutritional assessment allows measurement of changes in body composition variables and associated functional changes that adversely affect clinical outcome. The measurement of height and weight and derivation of BMI often relies on the willingness of staff to comply. The lack of compliance may be due to a lack of insight into the need to record such data. It may also be simply that the necessary equipment is not available in clinics or at ward level. Furthermore, equipment which is present may not be regularly calibrated or maintained. A study conducted for the British Association for Parenteral and Enteral Nutrition (Lennard-Jones et al. 1995) found that most of the nurses and doctors who were asked questions about the height and weight measurements of their patients had failed to measure them because they regarded them as unimportant. Of the wards surveyed $86 \%$ had weighing scales, but only just over half the hospitals had a service contract for their maintenance.

\section{Height}

The accurate measurement of a patient's height depends on the availability of either a fixed or portable stadiometer. In a survey of the nutritional status of 500 patients, 200 were found to be undernourished. Of these, only thirty-one $(15.5 \%)$ had their height measured at a clinic visit and one patient had height recorded on admission (McWhirter \& Pennington, 1994). In many situations a patient will be asked his height and will report that of his army measurements, data often 50 years out of date! Approximately only $50 \%$ of hospitalized patients will be able to have their height measured. An estimate of stature can be derived if it cannot be measured. One such highly correlated method for the estimation of height is knee height (Table 1). This is particularly useful in the elderly, those with severe spinal curvature or in patients who are unable to stand, and has been shown to be more accurate in these groups than arm span (Mitchell \& Lipschitz, 1982), with less interobserver variation (Chumlea et al. 1985a). Knee height is measured with a caliper in the left leg with the knee bent at a $90^{\circ}$ angle. Formulas are then used to estimate height in men and in women, with a $90 \%$ error of approximately $80 \mathrm{~mm}$ in both men and women.

\section{Weight}

Actual body weight and percentage weight loss are probably the most important indices of nutritional assessment, the most readily obtainable marker of energy reserves. However, because weight also reflects total body water, interpretation of weight and its fluctuations becomes more difficult in the acute setting where there is a relative increase in total body water, such as in hepatic, renal and cardiac disease.

Table 1. Estimation of stature from knee height (Ross Laboratories, unpublished results) ${ }^{\star}$

\begin{tabular}{|c|c|c|}
\hline & $\begin{array}{c}\text { Age } \\
\text { (years) }\end{array}$ & Stature $(\mathrm{cm})$ \\
\hline Males & $\begin{array}{l}19-59 \\
60-80\end{array}$ & $\begin{array}{l}\text { (knee height }(\mathrm{cm}) \times 1.88)+71.85 \\
(\text { knee height }(\mathrm{cm}) \times 2.08+59.01\end{array}$ \\
\hline Females & $\begin{array}{r}19-59 \\
60-80\end{array}$ & $\begin{array}{l}\text { (knee height }(\mathrm{cm}) \times 1.86-(\text { age }(\text { years }) \times 0.05) \\
\quad+70.25 \\
(\text { knee height }(\mathrm{cm}) \times 1.91-(\text { age }(\text { years }) \times 0.17) \\
\quad+75.00\end{array}$ \\
\hline
\end{tabular}

*Ross Laboratories, Columbus, $\mathrm{OH}$, USA. 
Percentage weight change is the most commonly used dynamic measurement of nutritional status, with acute unintentional weight loss particularly associated with increased morbidity and mortality (Table 2 ). Weight loss can easily be determined if a patient's before and after weight has been recorded. Difficulty arises when the preillness weight is unknown, bearing in mind that patients at nutritional risk have often already lost weight. Discrepancy between actual and recalled weight is likely (Pirie $e t$ al. 1981); however, there is evidence that estimation of weight loss by patient recall is more useful than that obtained by using published ideal-weight tables (Morgan et al. 1980). It is important, when assessing the importance of weight loss, that the composition, the rate and the cause of the weight loss are investigated. Percentage weight loss detects patients who were previously overweight but have unintentionally lost weight quickly. Such individuals may have lost mainly lean body mass (Garrow, 1980).

\section{$B M I$}

Measurement of height and weight allows calculation of BMI, the most frequently used being the Quetelet index (weight $(\mathrm{kg})$ divided by height ${ }^{2}\left(\mathrm{~m}^{2}\right)$ ). This was primarily developed as an indicator of overweight and obesity (Table 3), although it is also a useful clinical calculation to determine body weight in relation to height. The normal range for BMI is $20-25 \mathrm{~kg} / \mathrm{m}^{2}$ (Gregory et al. 1990). Although it is not a sensitive indicator of protein-energy malnutrition, as it does not distinguish between depletion of fat and protein stores, it is recognized that individuals with a BMI of less than $20 \mathrm{~kg} / \mathrm{m}^{2}$ may be at risk of nutritional depletion. A limitation of its classification is that it may fail to identify developing depletion in subjects who have a BMI below $20 \mathrm{~kg} / \mathrm{m}^{2}$. Interpretation is complicated in any subject with wasting diseases or those with exceptionally large muscle mass. Its use in anorexia nervosa has been advocated (Llewellyn-Jones \& Abraham, 1984). However, its use can also be criticized, as it assumes that everyone of the same height has the same ideal body weight within an acceptable range.

A formula for the calculation of BMI in amputees has been proposed (Tzamaloukas et al. 1994).

\section{Anthropometric measurements}

Data gathered from these relatively inexpensive easilyperformed tests can be used in two ways, either as a measure of change in body composition using serial measurements

Table 2. Weight loss as a percentage of pre-iliness weight and interpretation

\begin{tabular}{ll}
\hline Wt change (\%) & \multicolumn{1}{c}{ Interpretation } \\
\hline$<5$ & Not significant (unless rapid or likely to be ongoing) \\
$5-9$ & Not serious (unless rapid or already malnourished) \\
$10-20$ & Clinically significant requires nutritional support \\
$>20$ & Severe, requires aggressive nutritional support \\
\hline
\end{tabular}

Table 3. Interpretation of BMI

\begin{tabular}{ll}
\hline BMI $\left(\mathrm{kg} / \mathrm{m}^{2}\right)$ & Interpretation \\
\hline$>40$ & Grade III obesity \\
$30-40$ & Grade II obesity \\
$25-30$ & Grade I obesity \\
$20-25$ & Normal range \\
$17-20$ & Underweight \\
$<17$ & Severely underweight \\
\hline
\end{tabular}

in an individual, with a baseline for reference, or in epidemiological studies where values are compared with tables of age- and sex- standardized values. Unfortunately, the accuracy of these relatively simple measurements can be compromised by a number of errors in technique. The standard tables used for comparison must be used with caution, as many were developed using narrowly-defined healthy populations. The problem with using serial data for comparison is the variance in individual measurements. The validity of skinfold measurements and mid-arm circumference (MAC) is enhanced when the measurements are carried out by skilled staff.

In experienced hands, the clinical use of mid-arm muscle circumference (MAMC) and triceps skinfold thickness (TSF) to estimate stores of muscle protein and fat compartments in the mid-arm is a useful component of nutritional assessment. It is the accessibility of the upper arm which makes them useful techniques for the assessment of severe protein-energy malnutrition. Both may be used in patients who are immobile or too ill to weigh, or have fluid imbalance making weight difficult to rely upon. Changes in measurements are slow, but it is useful to monitor the MAC and TSF of patients who are on long-term nutritional support in order to assess efficacy. The use of these measurements is based on the assumptions that the arm and muscle compartment have a circular cross-section and there is a symmetric distribution of fat around the arm and a constant value for bone area: muscle area (Heymsfield et al. 1984). Although direct measurement of fat, bone and muscle tissue by computed tomography has shown that these measurements have an error of 5-15\% (Heymsfield et al. 1982b), this degree of potential error is of little clinical significance.

The first use of upper arm anthropometry to identify protein-energy malnutrition in hospital patients revealed a prevalence of $50 \%$ in surgical (Bistrian et al. 1974) and $44 \%$ in medical patients (Bistrian et al. 1976). At the time the only standard data for comparison were those of Jelliffe (1966). More recently, a prevalence value of $40 \%$ clinical malnutrition has been identified (McWhirter \& Pennington, 1994) using more recent population data for the age range 18-74 years (Bishop et al. 1981) and for the elderly (Burr \& Phillips, 1984). Clinically, the interpretation of results is carried out using the definition of protein-energy malnutrition classified by percentile (Gray \& Gray, 1976).

Skinfold thickness. Several sites can be used for the measurement of fat stores. The triceps, biceps, subscapular and suprailiac crest are the most commonly used. Four-site anthropometry can be used to measure body composition by calculating body fat percentage (Durnin \& Womersley, 1974). However, in clinical practice the triceps is the most 
accessible site for a single indirect measurement of body fat. The measurement of TSF is taken on the upper nondominant arm posterior surface, with the patient standing with arm hanging loosely by the side during measurement. The observer grasps a vertical pinch of skin and subcutaneous fat between the thumb and forefinger, $10 \mathrm{~mm}$ above the mid-point mark. The skinfold is gently pulled away from the underlying muscle tissue, and the caliper jaw is placed over the skinfold at the mid-point while maintaining grasp of the skinfold. Three consecutive readings are taken to the nearest $1 \mathrm{~mm} 2$ or $3 \mathrm{~s}$ after applying the caliper. Intra-examiner and inter-examiner error can occur when measuring skinfolds. This is particularly difficult in subjects with fat, easily-compressed tissue (Lukaski, 1987). Intra-examiner errors are more likely to occur when repeated measurements on the same subject fail to agree. These are due to the fatness of the subject, the level of experience of the examiner and the skinfold site itself (Lohman, 1981). Many hospitalized patients are unable to stand, and so detailed methodology for the measurement of the triceps in the recumbent patient has been published (Jensen, 1981). It is possible to measure MAC circumference and TSF accurately in the supine subject without significant systematic differences between standing and recumbent measurement (Chumlea et al. 1985b). Interexaminer errors, where two or more examiners measure a site, are usually larger, but with experience can be reduced to within $2 \mathrm{~mm}$ (Burkinshaw et al. 1973).

Mid-arm circumference. MAC is measured with a nonstretch plastic tape-measure at the mid-point of the upper arm between the acromion process and the tip of the olecranon.

Mid-arm muscle circumference. The measurement of the circumference of the arm (MAC) at the same point that the TSF is measured is used to derive the MAMC using the following formula (Heymsfield et al. 1982a):

$$
\operatorname{MAMC}(\mathrm{cm})=\operatorname{MAC}(\mathrm{cm})-\pi \times \operatorname{TSF}(\mathrm{cm}) \text {. }
$$

Results are compared with population-based standards classified by percentile. The $\mathrm{CV}$ for the measurement of MAMC is less than that for TSF, but the problems associated with its measurement are similar.

Anthropometry in the clinical setting. Interpretation of nutritional assessment in disease states may be difficult. Protein-energy malnutrition is common in end-stage liver disease (Hehir et al. 1985). There is a lack of sensitivity provided by individual nutritional indices: percentage ideal body weight was shown to be less than $85 \%$ of standard in most patients, reflecting increased total body water, mean TSF measurements were $49 \%$ of standard and MAMC were $78 \%$ of standard, and mean serum albumin was $27 \mathrm{~g} / \mathrm{l}$. Measurement of MAMC was the most sensitive marker. In a survey of fifty-four patients with cancer cachexia, most had a creatinine:height index of $<80 \%$ of standard, $42 \%$ had TSF $<80 \%$ of standard and $23 \%$ had MAMC $<80 \%$ of standard, as well as low serum albumin concentrations (Nixon et al. 1980). Creatinine:height index was considered to be the most sensitive marker. It has been demonstrated that patients with chronic renal failure suffer from nutritional depletion. In a study of forty-three insulin-dependent diabetic patients on haemodialysis or peritoneal dialysis,
MAMC was $<5$ th percentile in almost half, $26 \%$ of patients had body weights $<85 \%$ of ideal, and serum albumin was within normal range (Miller et al. 1983). Interpretation of nutritional assessment requires knowledge of the body's response to injury as well as knowledge of the individual patient's disease state.

\section{Body composition assessment}

Determination of body composition provides insight into which components of the body are affected or altered during illness and change in nutritional status. Fat is a dispensable tissue, but in human subjects protein is not, therefore some determination of body composition is useful, particularly for patients on long-term nutritional support. There has been an enormous interest generated in the clinical measurement of body composition in recent years. In 1996 alone there were more than 400 scientific reports, 3900 papers and eighteen books published relating to body composition (Heymsfield et al. 1997). Currently-available in vivo body composition methods are 'indirect'. The body component of interest cannot be weighed (e.g. fat-free body mass), but may be derived from the measurement of another component (e.g. total body water). Regression analysis is then used to develop prediction equations which can then be used in cross-validation of a new subject group.

The techniques used are difficult to perform in the clinical situation and are most often reserved for the research and laboratory situation. More recently 'bed-side' methods have been developed. One of these is bioelectrical impedance analysis (BIA). BIA is safe and non-invasive (Lukaski, 1986). It is convenient to use by being easily portable and inexpensive compared with direct body composition techniques. The technique measures the impedance of the body to a flow of a weak electrical current $(800 \mu \mathrm{A}, 50 \mathrm{kHz})$, assumed to be proportional to the square of the height of the subject, divided by its volume. The resistive component of body impedance between the right wrist and right ankle is then measured to the nearest $1 \Omega$. The lowest resistance value for an individual is used to calculate the conductivity (height ${ }^{2} /$ resistance). From the impedance, total body water and fat-free mass are calculated. Total body water is assumed in the healthy individual to be $72-74 \%$ of the fat-free mass (Panaretto, 1968). The equations for the normal population have been widely used and validated (Lukaski et al. 1985). However, as the technique assumes a steady hydration state, it has been suggested that the method is invalid in any clinical state which may alter the hydration status (Khaled et al. 1988). The sick or malnourished patient is affected by water and electrolyte disturbances, therefore the body composition is likely to be significantly different from that of the normally-nourished patient. BIA is also likely to be inaccurate during the refeeding of the severelymalnourished patient. The precision of predicting fat-free mass from BIA is enhanced by using specific equations for groups of populations that are homogenous in terms of age, sex and physiological status.

Attempts have been made to cross-validate BIA in several populations with medical conditions. BIA cannot answer questions related to the clinical management of a patient, nor can these measurements affect clinical outcome. 
These are potential areas of clinical research. BIA was found to be unreliable in patients with end-stage renal disease for estimation of lean body mass (Kerr et al. 1996), although it has opportunities for non-invasive assessment of fluid volume and its distribution (Lukaski, 1997). Previous workers had shown CV below $4 \%$ and suggested BIA as a reliable nutritional assessment method in haemodialysis patients (Cherlow et al. 1995). Values for body cell mass did not change in cirrhotic patients with ascites following paracentesis, therefore concluding that in this group of patients, anthropometry was the preferable nutritional assessment method (Cabre et al. 1995). It has been suggested that BIA is a useful adjunctive method for evaluation and monitoring of nutritional status of critically-ill patients (Robert et al. 1993). BIA has also been found to correlate well with the ${ }^{2} \mathrm{H}$ dilution method in patients with cystic fibrosis (Borowitz \& Conboy, 1994) and may be useful as a predictor of progressive undernutrition and poor growth in cystic children (Quirk et al. 1997). General surgical patients have been investigated (Fearon et al. 1992), as have malnourished patients with Crohn's disease (Royall et al. 1994). Prediction equations from validation work carried out on a population over the age of 60 years have been published (Deurenberg et al. 1989).

Although BIA has been promoted by several manufacturers as having the ability to determine body composition in a wide variety of clinical groups, such as the obese, intensive care, renal and diabetic patients, it is important to be wary of these results. There are significant errors associated with the use of the method in patients with disturbed fluid or electrolyte balance (Khaled et al. 1988). The loss of body tissue and the accumulation of extracellular fluid will lead to a high estimation of total body water, hence a high assessment of fat-free mass and a low estimation of fat mass. Thus, there remains a need for research to determine the validity of BIA in patients who are malnourished or undergoing nutritional therapy. The manufacturers' software prediction equations should be used with caution, as they are based on normal volunteers and therefore may be inappropriate for use in the clinical setting.

\section{Biochemical assessment}

There is no single universally-accepted objective biochemical marker of nutritional status. The indications and limitations of the commonly-used biochemical indices of nutritional status such as albumin and pre-albumin, transferrin and retinol-binding protein have been reviewed (Benjamin, 1989).

Albumin. Serum albumin was one of the first biochemical markers of nutritional status to be used. Its use as a nutritional marker has arisen from the confusion with its use as a prognostic indicator, for which there is strong evidence (Anderson \& Wochos, 1982). Protein-energy malnutrition causes a decrease in albumin synthesis rate (Fleck et al. 1985). Albumin has a very long half-life of $21 \mathrm{~d}$, responding slowly to altered protein intake. In the classic Minnesota experiment (Keys et al. 1950), after 24 weeks of semistarvation, serum albumin concentrations had only fallen by $10 \%$ and the total circulating albumin by $2 \%$. It was concluded that the drop in circulating plasma concentrations commonly seen in chronic diseases are not due to simple undernutrition. Normal albumin and serum protein concentrations are found in children suffering from marasmus. However, children with kwashiorkor have low albumin concentrations, the mechanism for which is unknown, but may be a reflection of the fact that oedema is present and therefore there is a dilution effect on plasma albumin concentrations (Gray \& Meguid, 1990). These children often have infections which may also contribute, as albumin is an acute-phase protein reflecting the illness of the patient. Low concentrations have also been correlated with increased morbidity and mortality in hospital patients and longer hospital stays (Ingenbleek et al. 1975; Dreblow et al. 1981).

Transferrin. The usefulness of serum transferrin has also been extensively investigated as a protein marker of nutritional status (Ingenbleek et al. 1975; Galina et al. 1987). It is synthesized by the liver and has a much smaller body pool than albumin. It is sensitive to protein status and has a shorter half-life $(8-10 \mathrm{~d})$. Its main function is to bind and transport Fe. It is therefore affected by Fe status. Fe deficiency results in an increase in hepatic synthesis, and consequent low concentrations are seen in many inflammatory states, liver disease, exogenous protein loss such as the nephrotic syndrome, and haemolytic anaemia. Its usefulness in nutritional assessment is limited, since concentrations are affected by the acute-phase response. It may be useful in epidemiological studies, but less so in individual patients.

Thyroxine-binding pre-albumin. Pre-albumin has a shorter half-life than albumin $(2 \mathrm{~d})$. It is synthesized in the liver and has a very small pool size. Pre-albumin responds acutely when energy and/or protein intakes are low. Its usefulness as a marker of nutritional status has been investigated because of its rapid response to nutritional therapy (Carpentier et al. 1982). This sensitivity means that it is more likely to be an indicator of recent dietary intake than an accurate measure of nutritional status (Farthing, 1983). As it is also sensitive to inflammation, serum concentrations decrease dramatically because of the inhibition of protein synthesis.

Retinol-binding protein. Retinol-binding protein is also produced by the liver and has an extremely short half-life $(12 \mathrm{~h})$ and is present in very low serum concentrations. As it is responsible for the transport of vitamin $A$, it is affected by vitamin A deficiency as well as hyperthyroidism, $\mathrm{Zn}$ deficiency, liver disease and the acute-phase response. Although it has been investigated and used as a nutritional marker, it is present in very low concentrations and is technically difficult to measure. Retinol-binding protein is similar to pre-albumin in that it responds to recent dietary intake rather than being a marker of nutritional status (Shetty et al. 1979).

Insulin-like growth factor-1. The insulin-like growth factors (IGF) or somatomedins are a family of lowmolecular-weight peptides, produced by the liver. They are controlled by growth hormone, acting as regulators of cell growth. A number of studies have suggested that IGF-1, one of the somatomedins which has a half-life of a few hours, may be a useful objective indicator of nutritional status. The mechanism for the reported fall in concentration in malnutrition is as yet unknown; it may be simply a reflection 
of the general decrease in protein synthesis which accompanies malnutrition. Unlike albumin and other markers, it is thought to be unaffected by the acute-phase response, and may therefore be a more accurate reflection of nutritional status independent of disease activity. This assumption was the basis for a study by Unterman et al. (1985). The IGF-1 levels of thirty-seven malnourished patients were compared with conventional nutritional indices (albumin, transferrin and lymphocyte count). IGF-1 correlated with each $(P<0.02)$ and levels rose in six patients who were provided with nutritional support. IGF-1 has been evaluated as a nutritional index by comparing plasma concentrations with albumin, transferrin and body composition variables (total body water, total body $\mathrm{Na}$ and total body $\mathrm{K}$ ) in eighteen patients who were malnourished following bilio-pancreatic bypass (Minuto, 1989). These patients were not suffering from any inflammatory response or tumour activity, and so low concentrations of IGF-1 were attributed to malnutrition alone. There was significant correlation between nutritional status measured by albumin, transferrin and body composition markers in these patients. Poor correlation was found when IGF-1 was used as a static marker in patients in whom malnutrition was determined by anthropometry (McWhirter et al. 1995).

\section{Functional assessment}

Grip strength. Measurement of muscle function is important in the assessment of nutritional status, but the laboratory methods of assessing this are not suitable for practice in the acute setting. Malnutrition results in reduced muscle function, which may be reversed during nutritional support, although measurement of nutritional indices may take longer to improve (Lopez et al. 1982). Maximum voluntary grip strength measured using a dynamometer is a useful functional measurement. Grip strength is related to wholebody muscle mass assessed by creatinine excretion, limb muscle circumference and anthropometry (Hunt et al. 1985). Specificity and sensitivity are improved if age- and sex-standardized values are used for comparison. A grip strength of less than $85 \%$ of standard-for-age and -sex could be evidence of muscle protein depletion (Webb et al. 1989). Hand-grip strength has been shown to be a useful test of skeletal muscle function and of malnutrition associated with post-operative complications (Klidjian et al. 1980). It cannot be used in patients with some disabilities, e.g. arthritis, critically-ill or in-patients who have been prescribed muscle relaxants. Up to $10 \%$ of patients in the acute setting may be unable to comply with dynamometry (McWhirter, 1995). It may be useful in patients receiving long-term nutritional support.

\section{Summary}

Malnutrition in hospital is often unrecognized because nutrition is not a priority. If there are no doctor's orders to measure a patient's height or weight it is often not done, and lack of the necessary equipment and necessary skills needs to be addressed. Once the problem of data collection is dealt with, there needs to be an action plan of appropriate nutritional care, and follow-up measures taken to evaluate the effect of the nutritional support provided.

Simple bedside techniques of measuring nutritional status should be used to determine those patients at risk of developing nutrition-related complications, in order to reduce the incidence of pre- and post-surgical complications and mortality. Assessment of nutritional status combined with a plan for nutritional care of those at risk would be beneficial and cost effective.

The ideal nutritional assessment should be relatively inexpensive, minimally invasive, and the results should be accurate and reproducible. Measurements such as height, weight and BMI, skinfold thickness and upper arm muscle circumference are simple, quick, cheap and non-invasive methods of estimating weight-for-height, subcutaneous fat and somatic protein stores.

In the future, research may provide us with an optimal highly specific and sensitive cost-effective nutritional assessment tool which will allow accurate determination of nutritional status, and thereby enable quick and appropriate decisions to be made on the provision of nutritional support.

\section{References}

Anderson CF \& Wochos DN (1982) The utility of serum albumin values in the nutritional assessment of hospitalised patients. Mayo Clinic Proceedings 57, 181-183.

Benjamin DR (1989) Laboratory tests and nutritional assessment. Pediatric Clinics of North America 36, 140-159.

Bishop CW, Bowen PE \& Richley SI (1981) Norms for nutritional assessment of American adults by upper arm anthropometry. American Journal of Clinical Nutrition 34, 2530-2539.

Bistrian BR, Blackburn GL, Hallowell E \& Heddle R (1974) Protein status of general surgical patients. Joumal of the American Medical Association 230, 858-860.

Bistrian BR, Blackburn GL, Vitale J, Cochran D \& Naylor J (1976) Prevalence of malnutrition in general medical patients. Journal of the American Medical Association 253, 1567-1570.

Blackburn GL, Bistrian BR, Maini BS, Schlamm HT \& Smith MF (1977) Nutritional assessment of the hospitalised patient. Journal of Parenteral and Enteral Nutrition 1, 11-22.

Borowitz D \& Conboy K (1994) Are bioelectrical impedance measurements valid in patients with cystic fibrosis? Journal of Pediatric Gastroenterology and Nutrition 18, 453-456.

Bozzetti F (1987) Nutritional assessment from the perspective of a clinician. Journal of Parenteral and Enteral Nutrition 11, 115S-121S.

Burkinshaw L, Jones PRM \& Krupowicz DW (1973) Observer error in skinfold thickness measurements. Human Biology $\mathbf{4 5}$, 273-279.

Burr ML \& Phillips KM (1984) Anthropometric norms in the elderly. British Journal of Nutrition 51, 165-169.

Buzby GP, Mullen JL, Matthews DC, Hobbs CL \& Rosato EF (1980) Prognostic nutritional index in gastrointestinal surgery. American Journal of Surgery 139, 160-167.

Cabre E, de-Leon R, Planas R, Bertran X, Domenach E \& Gassull MA (1995) Reliability of bioelectrical impedance analysis as a method of nutritional monitoring in cirrhosis with ascites. Gastroenterology and Hepatology 18, 359-365.

Carpentier YA, Barthel J \& Bruyns J (1982) Plasma protein concentrations in nutritional assessment. Proceedings of the Nutrition Society 41, 405-408. 
Cherlow GM, Lowrie EG, Wilmore DW, Gonzalez J, Lew NL Ling J, Leboff MS, Gottlieb MN, Huang W \& Zebrowski B (1995) Nutritional assessment with bioelectrical impedance analysis in maintenance hemodialysis patients. Journal of the American Society of Nephrology 6, 75-81.

Chumlea WC, Roche AF \& Steinbaugh ML (1985a) Estimating stature from knee height for persons 60 to 90 years of age. Journal of the American Geriatric Society 33, 116-120.

Chumlea WC, Roche AF, Steinbaugh ML \& Mukherjee D (1985b) Errors of measurement for methods of recumbent nutritional anthropometry in the elderly. Journal of Nutrition in the Elderly 5, 3-11.

Dempsey DT \& Mullen Л (1987) Prognostic value of nutritional indices. Journal of Parenteral and Enteral Nutrition 11, 109S$114 \mathrm{~S}$.

Dempsey DT, Mullen JL \& Buzby GP (1988) The link between nutritional status and clinical outcome: can nutritional intervention modify it? American Journal of Clinical Nutrition 47, 352-356.

Deurenberg P, Kooy K, Evers P \& Hulshof T (1989) Assessment of body composition by bioelectrical impedance in a population aged $>60$ years. American Joumal of Clinical Nutrition 51, 3-6.

Dreblow DM, Anderson CF \& Moxness K (1981) Nutritional assessment of orthopedic patients. Mayo Clinic Proceedings 56, 51-55.

Durnin JVGA \& Womersley J (1974) Body fat assessed from total body density and its estimation from skinfold thickness: measurement on 481 men and women aged from 16 to 72 years. British Journal of Nutrition 32, 77-97.

Farthing MJG (1983) Serum thyroxine binding pre-albumin may reflect energy and nitrogen intake rather than overall nutritional status in chronic intestinal disease. Nutrition Research 3, 618.

Fearon KCH, Richardson RA \& Hannan J (1992) An evaluation of bioelectrical impedance analysis in the measurement of the body composition of surgical patients. British Journal of Surgery 79, $421-423$.

Fleck A, Colley CM \& Myers MA (1985) Liver export proteins and trauma. British Medical Bulletin 41, 265-273.

Galina DL, Ausman LM, Kriauciunas K \& Hegsted DM (1987) Dissociated response of plasma albumin and transferrin to protein energy restriction in squirrel monkeys. American Journal of Clinical Nutrition 46, 941-948.

Garrow IS (1980) Combined medical-surgical approaches to treatment of obesity. American Joumal of Clinical Nutrition 33, $425-430$.

Grant J, Custer PB \& Thurlow J (1981) Current techniques of nutritional assessment. Surgical Clinics of North America 61, $437-463$.

Gray CE \& Gray LK (1979) Validity of anthropometric norms used in the assessment of hospitalised patients. Joumal of Parenteral and Enteral Nutrition 3, 366-368.

Gregory J, Foster K, Tyler H \& Wiseman M (1990) Dietary and Nutritional Survey of British Adults. London: H.M. Stationery Office.

Gray GE \& Meguid MM (1990) Can total parenteral nutrition reverse hypoalbuminemia in oncology patients? Nutrition 6 , 225-228.

Hehir DJ, Jenkins RL, Bistrian BR \& Blackburn GL (1985) Nutrition in patients undergoing orthotopic liver transplant. Journal of Parenteral and Enteral Nutrition 9, 695-700.

Heymsfield SB, McManus CB, Seitz SB, Nixon DW \& Andrews JS (1984) Anthropometric assessment of adult protein-energy malnutrition. In Nutrition Assessment, pp. 27-82 [RA Wright, SB Heymsfield and CB McManus, editors]. Boston, MA: Blackwell Scientific.
Heymsfield SB, McManus CB, Smith J, Stevens V \& Nixon DW (1982a) Anthropometric measurement of muscle mass: revised equations for calculating bone free muscle area. American Journal of Clinical Nutrition 36, 680-690.

Heymsfield SB, Stevens V, Noel R, McManus CB, Smith J \& Nixon D (1982b) Biochemical composition of muscle in normal and semistarved human subjects: relevance to anthropometric measurements. American Journal of Clinical Nutrition 36, 131-142.

Heymsfield SB, Wang Z \& Baumgarter RN (1997) Human body composition: advances in models and methods. Annual Review of Nutrition 17, 527-558.

Hill GL, Blackett RL, Pickford I, Burkenshaw L, Young GA, Warren JB, Sharach CG \& Morgan DB (1977) Malnutrition in surgical patients - an unrecognised problem. Lancet i, 689-692.

Hunt D, Rowlands B \& Johnston D (1985) Hand grip strength - a simple prognostic indicator in surgical patients. Journal of Parenteral and Enteral Nutrition 9, 701-704.

Ingenbleek Y, Van den Schneck HG \& De Nayer P (1975) Albumin, transferrin and the thyroxin binding prealbumin/retinol binding protein (TBPA-RPB) complex in assessment of malnutrition. Clinica Chimica Acta 63, 61-65.

Jelliffe DB (1966) The Assessment of the Nutritional Status of the Community. WHO Monograph no. 53. Geneva: WHO.

Jensen TG (1981) A comparison of triceps skinfold and upper arm circumference measurements taken in standard and supine positions. Journal of Parenteral and Enteral Nutrition 5 , 519-521.

Kerr PG, Strauss BJ \& Atkins RC (1996) Assessment of nutritional status of dialysis patients. Blood Purification 14, 382-387.

Keys AJ, Brozek J, Henchel O, Michelson O \& Taylor HL (1950) In The Biology of Human Starvation, pp. 140-160 Minneapolis, MN: University of Minnesota Press.

Khaled MA, McCutcheon MJ, Reddy S, Pearman PL, Hunter GR \& Weinsier RL (1988) Electrical impedance in assessing human body composition: the BIA method. American Journal of Clinical Nutrition 47, 789-792.

Klidjian AM, Foster KJ, Kammering RM, Cooper A \& Karran SJ (1980) Relationship of anthropometric variables to serious post operative complications. British Medical Journal 281, 899901.

Lennard-Jones JE, Arrowsmith $\mathrm{H}$, Davison C, Denham AF \& Micklewright A (1995) Screening by nurses and junior doctors to detect malnutrition when patients are first assessed in hospital. Clinical Nutrition 14, 336-340.

Llewellyn-Jones D \& Abraham SF (1984) Quetelet index in anorexia nervosa. British Medical Joumal 288, 1800.

Lohman TG (1981) Skinfolds and body density and their relation to body fatness. A review. Human Biology 2, 181-225.

Lopez J, Russell DM, Whitwell J \& Jeejeebhoy K (1982) Skeletal muscle function in malnutrition. American Journal of Clinical Nutrition 36, 602-610.

Lukaski HC (1986) Validation of tetrapolar bioelectrical impedance method to assess human body composition. Journal of Applied Physiology 60, 1327-1332.

Lukaski HC (1987) Methods for the assessment of human body composition: traditional and new. American Journal of Clinical Nutrition 46, 537-556.

Lukaski HC (1997) Validation of body composition techniques in the dialysis population. ASAIO Journal 43, 251-255.

Lukaski HC, Johnson PE, Bolonchuk WW \& Lykken GI (1985) Assessment of fat free mass using bioelectrical impedance measurements of the human body. American Journal of Clinical Nutrition 41, 810-817. 
McWhirter JP \& Pennington CR (1994) The incidence and recognition of hospital malnutrition. British Medical Journal 308, 945-948.

McWhirter JP, Ryan MF \& Pennington CR (1995) An evaluation of insulin-like growth factor-1 as an indicator of nutritional status. Clinical Nutrition 14, 74-80.

McWhirter JP (1995) The clinical significance of malnutrition. MPhil Thesis, Glasgow Caledonian University.

Miller D, Levine S, Bistrian BR \& D'Elia J (1983) Diagnosis of protein calorie malnutrition in diabetic patients on haemodialysis and peritoneal dialysis. American Joumal of Clinical Nutrition 41, 810-817.

Minuto F (1989) Insulin-like growth factor-1 in human malnutrition: relationship with some body composition and nutritional parameters. Journal of Parenteral and Enteral Nutrition 13, 392-396.

Mitchell DO \& Lipschitz DA (1982) Detection of protein caloric malnutrition in the elderly. American Journal of Clinical Nutrition 35, 398-406.

Morgan DB, Hill GL \& Burkinshaw L (1980) The assessment of weight loss from a single measurement of body weight: the problems and limitations. American Journal of Clinical Nutrition 33, 2101-2105.

Nixon DW, Heymsfield SB, Cohen AE, Kutner MH, Ansley J, Lawson DH \& Rudman D (1980) Protein-calorie undernutrition in hospitalised cancer patients. American Joumal of Medicine 68, 683-690.

Panaretto BA (1968) Estimation of body composition by the dilution of hydrogen isotopes. In Body Composition in Animals and Man, pp. 200-217. Washington, DC: National Academy of Sciences, National Research Council.

Pirie P, Jacobs D \& Jeffrey R (1982) Distortion in self reported height and weight data. Joumal of the American Dietetic Association 78, 601-606.

Quirk PC, Ward LC, Thomas BJ, Holt TL, Shepherd RW \& Cornish BH (1997) Evaluation of bioelectrical impedance for prospective nutritional assessment in cystic fibrosis. Nutrition 13, 412-416.

Reilly HE, Martineau JK, Moran A \& Kennedy H (1995) Nutritional screening - evaluation and implementation of a simple nutritional risk score. Clinical Nutrition 14, 269-274.

Robert S, Zarowittz BJ, Hyzy R, Eichenhorn M, Peterson EL \& Popovich J (1993) Bioelectrical impedance assessment of nutritional status in critically ill patients. American Journal of Clinical Nutrition 57, 840-844.

Royall A, Greenberg GR, Allard JP, Baker JP, Harrison JE \& Jeejeebhoy KN (1994) Critical assessment of body composition measurements in malnourished subjects with Crohn's disease. American Journal of Clinical Nutrition 59, 325-330.

Shetty PS, Watrasiewicz KE \& Jung RT (1979) Rapid turnover transport protein: an index of subclinical protein-energy malnutrition. Lancet ii, 230.

Sizer T (editor) (1996) Standards and Guidelines for Nutritional Support of Patients in Hospital. A Report of a BAPEN Working Party. Maidenhead, Berks.: BAPEN.

Studley HO (1936) Percentage of weight loss: a basic indicator of surgical risk in patients with chronic peptic ulcer. Journal of the American Medical Association 106, 458-460.

Tzamaloukas AH, Patron A \& Malhotra D (1994) Body mass index in amputees. Joumal of Parenteral and Enteral Nutrition 18, 355-358.

Unterman TG \& Vazlues RM (1985) Usefulness of somatomedin$\mathrm{C}$ in nutritional assessment. American Journal of Medicine 78, 228-233.

Webb AE, Newman LA, Taylor M \& Keogh JB (1989) Hand Grip Dynamometry as a predictor of post operative complications. Reappraisal using age standardised grip strengths. Journal of Parenteral and Enteral Nutrition 13, 30-33.

World Health Organization (1973) Energy and Protein Requirements: Report of a Joint FAO-WHO ad hoc Expert Committee. Technical Report Series no. 522. Geneva: WHO. 